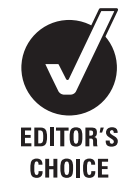

${ }^{1}$ UMR745 INSERM, Université Paris Descartes, Sorbonne Paris Cité, Faculté des Sciences Pharmaceutiques et Biologiques, Paris, France ${ }^{2}$ Service de Biochimie et de Génétique Moléculaire, Hôpital Cochin, AP-HP, Paris, France ${ }^{3}$ Département de Dermatologie, Centre de référence des neurofibromatoses, Hôpital Henri-Mondor, AP-HP and EA 4393 LIC, Université Paris Est Créteil (UPEC), Créteil, France

\section{Correspondence to}

Dr Eric Pasmant,

UMR745 INSERM, Université

Paris Descartes, Sorbonne Paris

Cité, Faculté des Sciences

Pharmaceutiques et

Biologiques, 4 avenue de

I'Observatoire, Paris 75006 ,

France;

eric.pasmant@parisdescartes.fr

Received 16 April 2012

Revised 25 June 2012

Accepted 26 June 2012

\title{
Neurofibromatosis type 1: from genotype to phenotype
}

\author{
Eric Pasmant, ${ }^{1,2}$ Michel Vidaud, ${ }^{1,2}$ Dominique Vidaud, ${ }^{1,2}$ Pierre Wolkenstein ${ }^{3}$
}

\section{ABSTRACT}

Although neurofibromatosis 1 (NF1) is a common

Mendelian disorder with autosomal-dominant inheritance, its expression is highly variable and unpredictable. Many NF1 patients have been genotyped but few allelephenotype correlations have been identified. NF1 genotype-phenotype correlations are difficult to identify because of the complexity of the NF1 phenotype, its strong age dependency, the relatedness of many clinical features and the huge heterogeneity of pathogenic NF1 mutations. Some NF1 patients with a given NF1 mutation may develop very severe disease while others with the same mutation have only mild symptoms. This phenotypic variability may be due to both modifier genes and environmental factors. Recent targeted strategies have identified several interesting candidate modifier genes.

\section{INTRODUCTION}

Neurofibromatosis type 1 (NF1; OMIM 162200) is an autosomal disorder with a worldwide birth incidence of 1 in 2500 and a prevalence of at least 1 in 4000. ${ }^{1} \mathrm{NF} 1$ is caused by dominant loss-of-function mutations of the tumour-suppressor gene NF1 (Neurofibromin 1; OMIM 613113) which encodes neurofibromin, a negative regulator of RAS proteins. The main clinical features of NF1 are multiple café-au-lait (CAL) spots, axillary freckling, Lisch nodules, optic pathway gliomas and peripheral nerve-sheath tumours. ${ }^{1-3}$ NF1 patients are at an increased risk of developing both benign and malignant tumours, and NF1 is thus classified as a tumour predisposition syndrome. Although NF1 is a simply determined Mendelian disorder with complete penetrance, it is characterised by highly variable expression and marked inter- and intrafamilial variation. $^{2}$ Some NF1 patients with a given mutation may develop very severe disease while others with the same mutation develop a mild form. The reasons for this clinical variability are poorly understood. Evidence for the existence of modifier genes has been obtained in large familial studies. ${ }^{2}{ }^{3}$ Recent targeted strategies have identified several candidate modifier genes, and it is hoped that the genomics revolution will lead to further rapid progress.

\section{PHENOTYPIC VARIABILITY IN NF1}

NF1 is a highly variable disease. It rapidly emerged that the nature of the NF1 gene mutation was not the only source of this variation, as considerable differences in clinical expression were noted within the same family. Indeed, Carey et al found that three-quarters of families showed marked interindividual differences in NF1 severity. ${ }^{1}$ The remainder of the phenotypic variability could be due to modifier genes, environmental factors or a combination of the two. The term 'modifier gene' is used here to denote any gene that influences one or several features of the NF1 phenotype. The word 'gene' is taken in its broad definition, including protein-coding sequences and microRNA and long non coding RNA genes that may modulate the NF1 phenotype. In principle, variations in the NF1 phenotype could be determined by a single modifier gene locus, or by interaction between several modifier genes. However, environmental factors might also contribute to the variable disease expression. Studies of NF1 clinical heterogeneity are hindered by the fact that the clinical course of a given patient may vary dramatically over his or her lifetime.

It is important to take other determinants into account when searching for modifier genes. For example, the average serum concentration of 25-hydroxy-vitamin D (25OHD), which plays a key role in bone metabolism and modulates the absorption of dietary calcium and phosphorus, is lower in NF1 patients than in individuals without NF1, ${ }^{4}$ and the incidence of fractures has been found to be higher than in siblings and spouses without NF1. ${ }^{5}$ Low 25OHD concentrations have been associated with tumours and osteopenia or fractures in adults with NF1. The serum 25OHD concentration has been found to correlate negatively with the number of dermal neurofibromas in NF1 patients. ${ }^{6}$ Another study showed low $25 \mathrm{OHD}$ concentrations in the majority of children with NF1, potentially because of increased pigmentation and/or decreased sunlight exposure. ${ }^{5}$ However, low $25 \mathrm{OHD}$ concentrations in children were not associated with neurofibromas, and 25OHD levels did not correlate with bone mineral density.

Age is the most important confounding factor in familial NF1 studies, many disease features being more prevalent in older patients. ${ }^{7}$ Somatic mosaicism in de novo NF1 cases must also be considered, because it may lead to milder or atypical NF1 phenotypes. ${ }^{8} 9$ In 2007 , germline dominant loss-of-function mutations in the SPRED1 gene were identified in patients fulfilling the US National Institutes of Health criteria for NF1, underlining a genetic heterogeneity for NF1 phenotype. $^{10}{ }^{11}$ Legius syndrome (caused by SPRED1 mutations) resembles a mild NF1 phenotype, with multiple CAL spots and macrocephaly, with or without axillary or inguinal freckling. By contrast, other typical features of NF1 (Lisch nodules, bone abnormalities, neurofibromas, optic pathway gliomas and malignant peripheral nerve sheath tumours (MPNST)) are lacking. 
If the phenotypic variability of NF1 is determined primarily by modifier genes, then the phenotypic intrafamilial correlation will decrease with the degree of relatedness. However, stronger correlations between close relatives than between distant relatives could also result from shared environmental influences. This pitfall can be avoided by comparing phenotypic correlations in monozygotic (MZ) twins and other siblings.

\section{FIRST CLUES: NATURAL HISTORY STUDIES}

Twin studies are a valuable tool for studying genetic disorders, particularly to estimate the heritability of clinical phenotypes. Heritability is defined as the proportion of phenotypic variance due to genetic variance. ${ }^{12} 13$ Twins are usually considered to share the same environment, independently of their zygosity. If MZ twins have a more similar clinical phenotype than dizygotic twins, this is likely to be explained by the effect of genetic modifiers on the clinical phenotype. There are at least 30 published case reports of MZ twins with NF1. Many MZ twins have very similar clinical features (CAL spots, axillary and inguinal freckling, Lisch nodules, epilepsy, non-dysplastic scoliosis, renal vascular hypertension, unilateral ptosis and cutaneous neurofibromas). ${ }^{2}{ }^{3}{ }^{14}$ In principle, this is explained by identical NF1 mutations, near-identical genomic backgrounds and very similar pre- and perinatal environments. Few $M Z$ twins with markedly different NF1 features have been described, ${ }^{15}$ but the causative mutations were not always identified. In a recent study of a pair of $M Z$ twins, only one of whom had a NF1 phenotype, a postzygotic NF1 gene mutation (leading to somatic mosaicism for the NF1 mutation) was exclusively identified in the affected twin. ${ }^{16}$ Plexiform neurofibromas tend to be less concordant than other features in twins with NF1. As the onset of many NF1-related tumours requires a second mutation in the wild-type NF1 allele, the sporadic nature of such mutations has been forwarded to explain this discrepancy. Other non hereditary factors could also influence tumour initiation and growth, such as epigenetic changes, somatic mutations in other tumour-related genes and environmental factors. A recent report describes a pair of $M Z$ twins with NF1 resulting from a de novo mutation, both of whom developed a left-sided sciatic plexiform neurofibroma that progressed to MPNST at a similar age, with pulmonary metastasis also occurring at the same age. ${ }^{14}$ However, data on $\mathrm{MZ}$ twins, although precious, should be interpreted with care. First, the sample size is always small, with only 10 pairs in the largest series. Second, certain complications of NF1 that require imaging studies (eg, whole-body MRI for internal plexiform neurofibromas) are not always documented. Finally, many twins are studied at a young age, and their subsequent course is not known.

Clues to the existence of modifier genes in NF1 have also been provided by studies of associations between NF1 clinical features. Szudek et al found significant associations between Lisch nodules, optic glioma, learning disability, macrocephaly and short stature in affected parent-child pairs, but they did not adjust for the non-independence of multiple pairs of relatives from the same family or for associations between clinical features in patients. ${ }^{17} \mathrm{~A}$ later analysis examined correlations between NF1 features among relatives of various degrees and confirmed that genetic factors determined the onset of particular phenotypic features in NF1. ${ }^{18}$

\section{GENETIC COMPONENT OF VARIABLE EXPRESSION IN NF1}

Several studies of the contribution of genetic factors to the phenotypic variation of NF1 have examined NF1-related traits in large series of multiple-case NF1 families. The patterns of variable expression are subtle, hence data on a very large number of patients and/or very large families are required.

Only three studies have assessed the inherited component of variable expression in large cohorts of well-phenotyped NF1 families. ${ }^{2}{ }^{3} 18$ In 1993, Easton et al studied 175 NF1 patients belonging to 48 families, including six pairs of MZ twins, 76 pairs of sibs, 60 parent-offspring pairs, 54 pairs of second-degree relatives and 43 pairs of third-degree relatives. ${ }^{2}$ Eight clinical features of NF1 were scored, comprising three quantitative traits (number of CAL spots, cutaneous neurofibromas, and head circumference) and five binary traits (presence or absence of plexiform neurofibromas, optic gliomas, scoliosis, epilepsy and referral for remedial education). Significant intrafamilial correlations were found for the three quantitative traits. The correlation was strongest in $\mathrm{MZ}$ twins, followed by first-degree relatives and then by distant relatives. The strong correlation in $\mathrm{MZ}$ twins suggested a major genetic component in the variable expression, while the weak correlation between distant relatives suggested that the type of mutation at the NF1 locus itself played only a minor role. Easton et al concluded that the phenotypic expression of NF1 was largely determined by the genotype at modifier loci and that these modifier genes were trait-specific

About 10 years after the study by Easton et al, a second large familial phenotype correlation study was published. ${ }^{18}$ Szudek et al examined familial aggregation of NF1 features among 904 affected individuals belonging to 373 families with two or more affected members (346 families were nuclear families that included either an affected parent and one or more affected children, or two or more affected sibs). The study population was five times larger than that of Easton et al, and 10 clinical features were examined (CAL spots, intertrigous freckling, Lisch nodules, cutaneous neurofibromas, subcutaneous neurofibromas, plexiform neurofibromas, seizures, scoliosis, optic glioma and other neoplasms). All the phenotypic traits were treated as binary variables, and multivariate regression was used to measure associations between various classes of relatives for each feature. As Easton et al had previously noted, the familial patterns suggested that most of the studied clinical features had important genetic components but that their relative contribution differed according to the feature in question.

These two studies thus demonstrated a strong genetic component in NF1 variability but both suffered from certain limitations. Easton et al examined a limited number of patients, while Szudek et al, although studying a larger number of patients, could not investigate many distant relatives, owing to the small number of extended families. Moreover, this latter study did not consider CAL spots and dermal neurofibromas (major manifestations of NF1) as quantitative variables but as binary traits. In a third large familial phenotype study, Sabbagh et al used variance components analysis, based on maximum likelihood procedures, to estimate the proportion of phenotypic variation attributable to genetic effects. ${ }^{3}$ Patterns of familial correlations were examined for 12 clinical features, including five quantitative traits (numbers of small and large CAL spots and cutaneous, subcutaneous and plexiform neurofibromas) and seven binary traits. These traits were scored in 750 NF1 patients from 275 multiplex families. With the exception of malignant neoplasms, all these features showed significant familial aggregation after adjustment for age and sex, that is, a particular feature was more likely to be present in close relatives than in the NF1 general population. The patterns of familial correlation indicated a strong genetic component for 
most features, with no apparent influence of the constitutional NF1 mutation. In accordance with the findings of Szudek and Easton, several statistically significant associations between combinations of clinical features were also found, suggesting that some NF1 features may share common genetic determinants. These results indicated a possible common repertoire of genetic modifiers for some trait combinations.

By analysing phenotype correlations in well-phenotyped NF1 families, these three large studies provided further evidence that genetic modifiers contribute to the variable expression of NF1. ${ }^{2} 318$ This has since been confirmed by studies of NF1 mouse models.

\section{NF1 MOUSE MODELS: CONFIRMATION OF THE EXISTENCE OF MODIFIER GENES}

Mice heterozygous for an $N f 1$ 'knockout' mutation $\left(N f 1^{+/-}\right)$ are viable, fertile and cancer-prone, like their human counterparts. ${ }^{19}$ However, these animals do not develop some hallmark features of the human disease, including neurofibromas and MPNSTs. The lack of neurofibromas in $N f 1^{+/-}$mice was attributed to the very low frequency of inactivation of the remaining functional Nf1 allele in Schwann cells. The frequency of a second-hit mutation was therefore proposed to be the ratelimiting event in the onset of neurofibromas and MPNSTs in mice. Mismatch-repair genes $(M M R)$ have been proposed as putative modifier genes influencing the NF1-associated tumour frequency in humans. In addition, a low frequency of neurofibromas is observed in zebrafish with knockout mutations of three major $M M R$ genes (mlh1, msh2, and msh6). ${ }^{20}$

\section{MOUSE GENETIC BACKGROUND AND NF1-ASSOCIATED TUMOUR SUSCEPTIBILITY}

The frequent coexistence of NF1 and TP53 mutations in human MPNSTs suggested that these mutations could cooperate to promote MPNSTs. Nf1 and Trp53 are close together on the mouse chromosome 11. Mating of $N f 1^{+/-}$and $\operatorname{Trp} 53^{+/-}$ mice resulted in $\mathrm{Nf1}{ }^{+/-} ; \operatorname{Trp} 53^{+/-}$trans mice that exhibited increased susceptibility to MPNSTs. ${ }^{21}$ This susceptibility was further increased in $\mathrm{Nf1}^{+/-} ; \operatorname{Trp} 53^{+/-}$cis mice carrying the two mutant alleles on the same chromatid. ${ }^{21}$ Moreover, $\mathrm{Nf1^{+/- }}$; $\operatorname{Trp} 53^{+/}$cis mice spontaneously develop cancers associated with the human NF1 syndrome, including astrocytomas. ${ }^{22} 23$ This was consistent with the observation that the Nf1 and Trp53 wild-type alleles could both be lost in a single genetic event in $\mathrm{Nf}^{+/-}$; Trp $53^{+/-}$cis mice. These results confirmed that homozygous mutations in the NF1 and TP53 tumour-suppressor genes cooperate in the development of MPNSTs. Moreover, tumour susceptibility appeared to be dependent on the genetic background of mice carrying the Nf1 and Trp53 cis mutations. ${ }^{22}{ }^{23}$ It was therefore postulated that tumour susceptibility might be influenced by $N f 1$ expression levels. Hawes et al examined levels of Nf1 gene expression in mouse strains with different degrees of tumour susceptibility. ${ }^{24}$ They found that the strain background had as much an effect on Nf1 expression levels as did mutation of one $N f 1$ allele, indicating that animal studies of haploinsufficiency must be interpreted carefully with respect to the strain background. Because Nf1 expression levels did not correlate perfectly with strain susceptibility to tumours, it was suggested either that variations in Nf1 expression levels were not responsible for the differences in astrocytoma susceptibility in $N f 1^{-/+} ; \operatorname{Trp} 53^{-/+}$cis mice, or that certain mouse strains had evolved mechanisms to compensate for differences in Nf1 expression. Interestingly, one of the strongest determinants of astrocytoma and MPNST tumour susceptibility was inheritance of the Nf1;Trp53 mutant chromosome from the mother or father. ${ }^{23} 25$ It has been postulated that an imprinted gene on chromosome 11 may be responsible for these differences in susceptibility. However, no modifier gene responsible for variations in tumour susceptibility in Nf1:Trp53 cis mice were identified in a recent study using real-time PCR to test many of the imprinted candidate genes on mouse chromosome 11. ${ }^{26}$ However, mapping of modifiers in $\mathrm{Nf1}{ }^{+/-} ; \operatorname{Trp} 53^{+/-}$cis mice has led to the identification of several loci, unlinked to chromosome 11, that are responsible for susceptibility to MPNST and astrocytomas in backcross populations. ${ }^{25}$ Two nerve sheath tumour resistance (Nstr) loci were identified: one near the centromere of chromosome 19 (Nstr1), and one at the proximal end of chromosome 15 (Nstr2). ${ }^{25}$ Nstr1 is syntenic with human chromosome 11q13-12, a region involved in translocations found in human MPNSTs. Nstr2 is syntenic with human chromosome regions 5p13-15 and 8q22-24. Human chromosome region $8 \mathrm{q} 22-23$ is often amplified in MPNSTs and is also subject to translocation. Nstr1 and Nstr2 may act epistatically, with inheritance of the mutant chromosome 11 from the mother or father. Further work is required to confirm this strain-background effect, and the mechanisms underlying the effect of modifier genes on the tumour spectrum.

Mouse models do not currently mimic the full human NF1 phenotype. For example, mice lacking the alternatively spliced Nf1 exon 23a show specific learning impairments. ${ }^{27}$ In humans, exon $23 \mathrm{a}$ is predominantly included in most tissues and specifically skipped in central nervous system neurons. It is possible that alteration of alternative splicing could have a role as a genetic modifier of the learning disabilities in NF1 patients. A human-centered genetic approach will be necessary to identify NF1 modifier genes.

\section{GENOTYPE-PHENOTYPE CORRELATIONS IN NF1}

Phenotypic studies of large cohorts suggest that the type of mutation in the NF1 gene does not account for the observed phenotype variability, 318 and this was confirmed by genotype-phenotype correlation studies.

In addition to modifier genes, allelic heterogeneity of constitutional NF1 mutations could also contribute to disease variability. Almost half of all NF1 cases result from sporadic mutations, and a huge number of NF1 pathogenic mutations have been reported, hindering genotype-phenotype correlation studies. Between $5 \%$ and $10 \%$ of pathogenic mutations are large $17 q 11$ deletions encompassing the entire NF1 locus and neighbouring genes. Since their initial description in 1992, NF1 deletions have been linked to a more severe clinical phenotype than intragenic NF1 mutations. This 'contiguous gene syndrome' appears to include dysmorphic features, learning disabilities, cardiovascular malformations, childhood overgrowth, a higher burden of cutaneous neurofibromas, earlier onset of benign neurofibromas and, probably, a higher incidence of MPNSTs. ${ }^{28-30}$ Some authors have speculated that increased malignancy may be explained by variations in the expression of tumour suppressor genes located in co-deleted regions. ${ }^{31} 32$

In patients with intragenic NF1 mutations ( $>90 \%$ of cases), no clear-cut allele-phenotype correlations have so far been established, with the exception of a 3-bp inframe deletion (c.2970-2972 delAAT) in exon 17, which has been linked to a particular clinical phenotype characterised by the absence of cutaneous neurofibromas. ${ }^{33}$ Other studies have attempted to identify genotype-phenotype correlations in patients with atypical NF1 phenotypes and/or mutation types. Patients with multiple spinal tumours but few or no other clinical features of 
NF1 have been described, forming a subgroup or distinct genetic form of NF1 called spinal neurofibromatosis. ${ }^{34-36}$ Several studies have shown that patients with spinal tumours can have various NF1 symptoms and NF1 mutations. A recent publication reported a trend towards clustering of pathogenic changes in the $5^{\prime}$ tertile of the NF1 gene in patients with optic pathway gliomas. ${ }^{37}$

\section{INVOLVEMENT OF UNLINKED MODIFIER GENES IN PHENOTYPIC VARIABILITY}

The role of the normal (wild-type) NF1 allele (in trans to the primary mutation) in the variable expression of NF1 was recently investigated in a family-based association study. ${ }^{3}$ Nine tag single-nucleotide polymorphisms (SNPs) in NF1 were genotyped in 1132 individuals from 313 NF1 families. No significant deviations of transmission of any of the NF1 variants to affected offspring was found for any of the 12 clinical features examined, based on single marker or haplotype analysis. This study provided evidence for a strong genetic component in most NF1 clinical features but no apparent influence of the NF1 gene: neither the constitutional NF1 mutation nor the normal NF1 allele seemed to contribute significantly to the overall phenotypic variation of each trait. However, alterations in expression levels of the wild-type NF1 allele were not excluded by this study. Recent reports concerning the functional structure of the human genome show that differences in transcription may also explain disease variability, and that the transcription domain of a given gene might extend very far beyond the usual regulatory sequences. This is in keeping with the different levels of $N f 1$ expression observed in mouse strain backgrounds with specific phenotypes. ${ }^{22}$ No determinants of NF1 transcript levels, which could be regarded as NF1 modifier genes, have yet been found.

\section{BIOLOGY-DRIVEN CANDIDATE GENE STRATEGY TO IDENTIFY MODIFIER GENES}

Strategies used to show the role of genetic factors in phenotypic expression can be classified into two categories: (i) a systematic approach in which the whole genome is scanned, and (ii) an approach focusing on candidate genes or pathways. ${ }^{38}$ The candidate-gene approach can be defined as the study of genetic determinants of a complex trait based on: (i) generating hypotheses and identifying candidate genes that might have a pathogenic role; (ii) identifying variants (SNPs) in or near these genes; and (iii) genotyping of variants in a population, followed by statistical methods (linkage or association) to identify correlations with the phenotype. ${ }^{39}$ Testing of variants in carefully selected candidates is attractive for several reasons: the number of variants is generally small, thereby avoiding severe penalties for multiple comparisons during the statistical analysis. A detailed understanding of the candidate gene product and its variants provides mechanistic insight and facilitates experimental studies to evaluate the modifier effects.

Several approaches can be used to select candidate genes. A deeper understanding of the biochemical functions of neurofibromin may lead to the discovery of interacting proteins and of upstream and downstream effectors that are critical for the development of particular phenotypic features. In both humans and mice, NF1 tumour development results from a combination of ubiquitous NF1 heterozygosity and unpredictable NF1 loss of heterozygosity in different cell lineages. ${ }^{40}$ Neurofibroma-derived Schwann cells harbouring two mutated NF1 alleles $\left(\mathrm{NF}^{-/-}\right)$have been isolated from several neurofibromas. Mitotic recombination is the likely mechanism underlying this loss of heterozygosity. ${ }^{41}$ As mitotic recombination shows inter-individual variation, genes that control this phenomenon may partly explain the variable number of neurofibromas in NF1 patients, by influencing the somatic mutation rate.

The variable number of NF1-associated neurofibromas could also be due to variable accumulation of somatic NF1 mutations. Two research groups have described the role of $M M R$ genes in neurofibroma development in NF1. ${ }^{42}$ Both provided evidence that a reduction in MMR capacity can result in NF1 mutations in a high percentage of neurofibromas. It has been postulated that constitutional or early alterations of $M M R$ genes in NF1 patients may lead to an accumulation of second hits in NF1, a human gene with one of the highest mutation rates. However, apart from one report, no constitutional mutations in $M M R$ genes have been detected in NF1 patients. ${ }^{44} \mathrm{~A}$ recent study examined whether increased tumour load in NF1 (higher number of cutaneous neurofibromas) was associated with methylation of $M M R$ genes. ${ }^{45}$ Titze et al performed methylation-specific PCR and pyrosequencing of $M M R$ gene promoters most frequently involved in human cancers (MLH1, MSH6, PMS2, and MSH2) in leukocytes of NF1 patients. They found that in NF1 patients with a high number of cutaneous neurofibromas versus those with a low, methylation of two (out of six) CpG dinucleotides in $M S H 2$ promoter was enhanced.

Biology-driven modifier genes have also been suggested to play a role in dermal neurofibromas. Dermal neurofibromas occur in virtually all individuals with NF1. Recent elegant studies have pointed to skin-derived neural progenitors (SKPs), or their derivatives, as the cell of origin of NF1-associated dermal neurofibromas. ${ }^{46}$ When Nf1-homozygous SKPs were autologously implanted intradermally in mice, they only gave rise to dermal neurofibromas in female mice that were pregnant at the time of implantation, and not in males or non pregnant females. This suggested that the hormonal environment may be a critical factor in the onset of dermal neurofibromas. NF1 patients typically begin to develop dermal neurofibromas around puberty, and the number and size of neurofibromas increases during pregnancy. ${ }^{47}$ McLaughlin et al reported that $5 \%$ of human neurofibromas express the oestrogen receptor (ER), while $75 \%$ express the progesterone receptor. ${ }^{49}$ Studies have confirmed steroid hormone receptor expression and ligandmediated cell growth and survival in both normal human Schwann cells and neurofibroma-derived Schwann cell cultures. ${ }^{50}$ Moreover, an increased potential for malignant transformation of plexiform neurofibromas has been reported during pregnancy. ${ }^{51}$ The selective ER modulator tamoxifen has been tested for its ability to inhibit MPNST tumourigenesis. Tamoxifen showed potent antitumor activity in mice orthotopically xenografted with human MPNST cells, providing a rationale for clinical trials. ${ }^{52}$ Thus, steroid hormones may directly influence neurofibroma initiation or progression by acting through their cognate receptors, but these effects may only apply to a subset of tumours. ${ }^{50}$

Because of their co-localisation with neurofibromin, mitochondria are also attractive NF1 modifier candidates. In Drosophila, neurofibromin regulates longevity and stress resistance through CAMP regulation of mitochondrial respiration and ROS production. ${ }^{53}$ Recently, the role of mitochondria in tumour development has gained much attention, with reports of somatic mitochondrial DNA (mtDNA) mutations in several human cancers. ${ }^{54}$ Somatic mtDNA mutations have also been described in NF1-associated neurofibromas. ${ }^{55}$ Moreover, variations in mtDNA copy numbers are increasingly reported in a range of primary human cancers, suggesting that they may be 
critical for cancer pathogenesis and progression. ${ }^{56}$ Mitochondria contain multiple copies of circular double-stranded DNA molecules that exhibit a high degree of sequence variation across individuals. Detjen et al studied nucleated blood cells from four pairs of NF1 discordant MZ twins and from cutaneous neurofibromas of one twin pair, but failed to find evidence of mtDNA sequence differences or different degrees of heteroplasmy. ${ }^{57}$

\section{IDENTIFICATION OF CANDIDATE MODIFIER GENES IN NF1: PROOF OF CONCEPT}

In a recent study, Pasmant et al used whole-genome high-resolution array-comparative genomic hybridisation of NF1-associated plexiform neurofibromas to identify candidate modifier genes. ${ }^{58}$ For the first time, 9 p21.3 deletions were identified as the only recurrent somatic alterations in these tumours. The smallest common deleted region in 9p21.3 included the CDKN2A-CDKN2B-ARF gene cluster and the ANRIL gene, a large non coding RNA. This recurrent 9p21.3 deletion was also found in a series of atypical neurofibromas (symptomatic hypercellular benign peripheral nerve sheath tumours) but not in dermal or plexiform tumours, in an independent study. ${ }^{59}$ A family-based association study ${ }^{60}$ was then carried out using tag SNPs located in region 9p21.3 in 1105 subjects from 306 families. Allele T of SNP rs2151280 (located in ANRIL) was strongly associated with a larger number of plexiform neurofibromas. ${ }^{58}$ No such association was observed with dermal neurofibromas. However, the ANRIL SNP rs2151280 has not been tested for its possible functional effects on neurofibroma formation. To confirm the role of rs2151280, CDKN2A, $C D K N 2 B, A R F$ and ANRIL expression was analysed in 124 NF1 patients' peripheral blood cells. Allele T of rs2151280 was significantly associated with reduced ANRIL transcript levels. ${ }^{58}$ This study demonstrated the relevance of whole-genome characterisation for the identification of candidate modifier genes in plexiform neurofibromas. Targeted strategies hold great promise for the identification of novel genetic variants responsible for the heritable features and complications of NF1. However, this candidate-gene approach has been criticised for its poor reproducibility and its inability to include all possible causative genes and polymorphisms. ${ }^{38} \mathrm{New}$ genome-wide techniques may overcome these limitations.

\section{FROM GENETICS TO GENOMICS: PROMISE OF GENOME-WIDE ASSOCIATION STUDIES AND NEXT-GENERATION SEQUENCING IN NF1}

Low-cost genotyping arrays allow researchers to perform unbiased genome-wide association studies (GWAS). GWAS can scan millions of common SNPs for their association with human complex traits. ${ }^{61} 62$ The repertoire of common human DNA sequence variants now provides good coverage of all common variations of the human genome. ${ }^{63}$ One strategy is to study a small number of subjects with high-density genomewide technologies, followed by additional subjects and/or additional SNPs at regions of interest thus identified. With the advent of next generation sequencing (NGS) methods and data from the 1000 Genomes Project, ${ }^{64}$ investigators must choose among (or combine) multiple strategies for creating and testing a reference panel of polymorphic sites. ${ }^{65}$ Genome-wide methods hold great promise for identifying modifier genes in NF1.

\section{CONCLUSION}

Cohort studies have shown that the clinical expression of NF1 tends to be similar in close relatives, but this similarity falls well short of that required for prognostication. The relatively minor contribution of variations at the NF1 locus to disease expression suggests that precise knowledge of NF1 mutations will generally be unhelpful.

The first and probably the most important step in the search for modifier genes is to select a particular clinical trait and the most relevant study population. The NF1 manifestations should be differentiated at different levels (features, consequences, and complications) in order to precisely define the relation between genetic modifiers and phenotypic characteristics. ${ }^{66}$

Modifier genes often have at least two alleles, one of which exacerbates the disease and one that suppresses it by raising the threshold for trait expression. Mimicking and perhaps enhancing the effects of naturally occurring genetic modifiers might lead to new therapeutics. A better understanding of the basis for variable disease presentation in general, and for disease suppression in particular, could improve the prediction, treatment and perhaps even the prevention of several NF1 complications. ${ }^{67}$

Contributors EP, MV, DV and PW wrote this review.

Competing interests None.

Provenance and peer review Not commissioned; externally peer reviewed.

\section{REFERENCES}

1. Carey JC, Baty BJ, Johnson JP, Morrison T, Skolnick M, Kivlin J. The genetic aspects of neurofibromatosis. Ann N Y Acad Sci 1986;486:45-56.

2. Easton DF, Ponder MA, Huson SM, Ponder BA. An analysis of variation in expression of neurofibromatosis (NF) type 1 (NF1): evidence for modifying genes. Am J Hum Genet 1993;53:305-13.

3. Sabbagh A, Pasmant E, Laurendeau I, Parfait B, Barbarot S, Guillot B, Combemale P, Ferkal S, Vidaud M, Aubourg P, Vidaud D, Wolkenstein P, members of the NF France Network. Unravelling the genetic basis of variable clinical expression in neurofibromatosis 1. Hum Mol Genet 2009;18:2768-78.

4. Tucker T, Schnabel C, Hartmann M, Friedrich RE, Frieling I, Kruse HP, Mautner VF, Friedman JM. Bone health and fracture rate in individuals with neurofibromatosis 1 (NF1). J Med Genet 2009;46:259-65.

5. Stevenson DA, Viskochil DH, Carey JC, Sheng X, Murray M, Moyer-Mileur L, Shelton J, Roberts WL, Bunker AM, Hanson H, Bauer S, D’Astous JL. Pediatric 25-hydroxyvitamin D concentrations in neurofibromatosis type 1. J Pediatr Endocrinol Metab 2011;24:169-74.

6. Lammert M, Friedman JM, Roth HJ, Friedrich RE, Kluwe L, Atkins D, Schooler T, Mautner VF. Vitamin D deficiency associated with number of neurofibromas in neurofibromatosis 1. J Med Genet 2006;43:810-13.

7. Cnossen M, de Goede-Bolder A, van den Broek K, Waasdorp C, Oranje A, Stroink $H$, Simonsz $H$, van den Ouweland A, Halley D, Niermeijer M. A prospective 10 year follow up study of patients with neurofibromatosis type 1. Arch Dis Child 1998;78:408-12.

8. Kehrer-Sawatzki H, Cooper DN. Mosaicism in sporadic neurofibromatosis type 1 : variations on a theme common to other hereditary cancer syndromes? J Med Genet 2008;45:622-31.

9. Messiaen L, Vogt J, Bengesser K, Fu C, Mikhail F, Serra E, Garcia-Linares C, Cooper DN, Lazaro C, Kehrer-Sawatzki H. Mosaic type-1 NF1 microdeletions as a cause of both generalized and segmental neurofibromatosis type-1 (NF1). Hum Mutat 2011;32:213-19.

10. Brems H, Chmara M, Sahbatou M, Denayer E, Taniguchi K, Kato R, Somers R, Messiaen L, De Schepper S, Fryns JP, Cools J, Marynen P, Thomas G, Yoshimura A, Legius E. Germline loss-of-function mutations in SPRED1 cause a neurofibromatosis 1-like phenotype. Nat Genet 2007;39:1120-6.

11. Pasmant E, Sabbagh A, Hanna N, Masliah-Planchon J, Jolly E, Goussard P, Ballerini P, Cartault F, Barbarot S, Landman-Parker J, Soufir N, Parfait B, Vidaud M, Wolkenstein P, Vidaud D, France RN. SPRED1 germline mutations caused a neurofibromatosis type 1 overlapping phenotype. J Med Genet 2009;46:425-30.

12. Vineis $\mathbf{P}$, Pearce N. Missing heritability in genome-wide association study research. Nat Rev Genet 2010;11:589.

13. Vineis $\mathbf{P}, \mathbf{E}$ Pearce N. Genome-wide association studies may be misinterpreted: genes versus heritability. Carcinogenesis 2011;32:1295-8.

14. Melean G, Hernandez AM, Valero MC, Hernandez Imaz E, Martin Y, Hernandez-Chico C. Monozygotic twins with neurofibromatosis type 1, concordant 
phenotype and synchronous development of MPNST and metastasis. BMC Cancer 2010;10:407

15. Rieley MB, Stevenson DA, Viskochil DH, Tinkle BT, Martin LJ, Schorry EK. Variable expression of neurofibromatosis 1 in monozygotic twins. Am J Med Genet $A$ 2011;155A:478-85.

16. Vogt J, Kohlhase J, Morlot S, Kluwe L, Mautner VF, Cooper DN, Kehrer-Sawatzki H. Monozygotic twins discordant for neurofibromatosis type 1 due to a postzygotic NF1 gene mutation. Hum Mutat 2011;32:E2134-47.

17. Szudek J, Birch P, Riccardi VM, Evans DG, Friedman JM. Associations of clinical features in neurofibromatosis 1 (NF1). Genet Epidemiol 2000;19:429-39.

18. Szudek J, Joe H, Friedman JM. Analysis of intrafamilial phenotypic variation in neurofibromatosis 1 (NF1). Genet Epidemiol 2002;23:150-64.

19. Jacks T, Shih TS, Schmitt EM, Bronson RT, Bernards A, Weinberg RA. Tumour predisposition in mice heterozygous for a targeted mutation in Nf1. Nat Genet 1994; 7:353-61.

20. Feitsma H, Kuiper RV, Korving J, Nijman IJ, Cuppen E. Zebrafish with mutations in mismatch repair genes develop neurofibromas and other tumors. Cancer Res 2008;68:5059-66.

21. Cichowski K, Shih TS, Schmitt E, Santiago S, Reilly K, McLaughlin ME, Bronson RT, Jacks T. Mouse models of tumor development in neurofibromatosis type 1. Science 1999;286:2172-6.

22. Reilly KM, Loisel DA, Bronson RT, McLaughlin ME, Jacks T. Nf1;Trp53 mutant mice develop glioblastoma with evidence of strain-specific effects. Nat Genet 2000;26:109-13.

23. Reilly KM, Tuskan RG, Christy E, Loisel DA, Ledger J, Bronson RT, Smith CD, Tsang S, Munroe DJ, Jacks T. Susceptibility to astrocytoma in mice mutant for Nf1 and Trp53 is linked to chromosome 11 and subject to epigenetic effects. Proc Natl Acad Sci USA 2004;101:13008-13.

24. Hawes JJ, Tuskan RG, Reilly KM. Nf1 expression is dependent on strain background: implications for tumor suppressor haploinsufficiency studies. Neurogenetics 2007;8:121-30

25. Reilly KM, Broman KW, Bronson RT, Tsang S, Loisel DA, Christy ES, Sun Z, Diehl J Munroe DJ, Tuskan RG. An imprinted locus epistatically influences Nstr1 and Nstr2 to control resistance to nerve sheath tumors in a neurofibromatosis type 1 mouse model. Cancer Res 2006;66:62-8.

26. Tuskan RG, Tsang S, Sun Z, Baer J, Rozenblum E, Wu X, Munroe DJ, Reilly KM. Real-time PCR analysis of candidate imprinted genes on mouse chromosome 11 shows balanced expression from the maternal and paternal chromosomes and strain-specific variation in expression levels. Epigenetics 2008;3:43-50.

27. Costa RM, Yang T, Huynh DP, Pulst SM, Viskochil DH, Silva AJ, Brannan Cl. Learning deficits, but normal development and tumor predisposition, in mice lacking exon 23a of Nf1. Nat Genet 2001;27:399-405.

28. Castle B, Baser ME, Huson SM, Cooper DN, Upadhyaya M. Evaluation of genotype-phenotype correlations in neurofibromatosis type 1. J Med Genet 2003;40:e109.

29. Mautner VF, Kluwe L, Friedrich RE, Roehl AC, Bammert S, Högel J, Spöri H, Cooper DN, Kehrer-Sawatzki H. Clinical characterisation of 29 neurofibromatosis type-1 patients with molecularly ascertained 1.4 Mb type-1 NF1 deletions. J Med Genet 2010;47:623-30.

30. Pasmant E, Sabbagh A, Spurlock G, Laurendeau I, Grillo E, Hamel MJ, Martin L, Barbarot S, Leheup B, Rodriguez D, Lacombe D, Dollfus H, Pasquier L, Isidor B, Ferkal S, Soulier J, Sanson M, Dieux-Coeslier A, Bièche I, Parfait B, Vidaud M, Wolkenstein P, Upadhyaya M, Vidaud D, members of the NF France Network. NF1 microdeletions in neurofibromatosis type 1: from genotype to phenotype. Hum Mutat 2010;31:E1506-18

31. Bartelt-Kirbach B, Wuepping M, Dodrimont-Lattke M, Kaufmann D. Expression analysis of genes lying in the NF1 microdeletion interval points to four candidate modifiers for neurofibroma formation. Neurogenetics 2009;10:79-85.

32. Pasmant E, Masliah-Planchon J, Lévy P, Laurendeau I, Ortonne N, Parfait B, Valeyrie-Allanore L, Leroy K, Wolkenstein P, Vidaud M, Vidaud D, Bièche I. Identification of genes potentially involved in the increased risk of malignancy in NF1-microdeleted patients. Mol Med 2011;17:79-87.

33. Upadhyaya M, Huson SM, Davies M, Thomas N, Chuzhanova N, Giovannini S, Evans DG, Howard E, Kerr B, Griffiths S, Consoli C, Side L, Adams D, Pierpont M, Hachen R, Barnicoat A, Li H, Wallace P, Van Biervliet JP, Stevenson D, Viskochil D, Baralle D, Haan E, Riccardi V, Turnpenny P, Lazaro C, Messiaen L. An absence of cutaneous neurofibromas associated with a 3-bp inframe deletion in exon 17 of the NF1 gene (c.2970-2972 delAAT): evidence of a clinically significant NF1 genotype-phenotype correlation. Am J Hum Genet 2007;80:140-51.

34. Kaufmann D, Müller R, Bartelt B, Wolf M, Kunzi-Rapp K, Hanemann CO, Fahsold R Hein C, Vogel W, Assum G. Spinal neurofibromatosis without café-au-lait macules in two families with null mutations of the NF1 gene. Am J Hum Genet 2001;69:1395-400

35. Kluwe L, Tatagiba M, Fünsterer C, Mautner V. NF1 mutations and clinical spectrum in patients with spinal neurofibromas. J Med Genet 2003;40:368-71.
36. Wimmer K, Mühlbauer M, Eckart M, Callens T, Rehder H, Birkner T, Leroy JG, Fonatsch C, Messiaen L. A patient severely affected by spinal neurofibromas carries a recurrent splice site mutation in the NF1 gene. Eur J Hum Genet 2002;10:334-8.

37. Sharif S, Upadhyaya M, Ferner R, Majounie E, Shenton A, Baser M, Thakker N, Evans DG. A molecular analysis of individuals with neurofibromatosis type 1 (NF1) and optic pathway gliomas (OPGs), and an assessment of genotype-phenotype correlations. J Med Genet 2011;48:256-60.

38. Génin E, Feingold J, Clerget-Darpoux F. Identifying modifier genes of monogenic disease: strategies and difficulties. Hum Genet 2008;124:357-68.

39. Tabor HK, Risch NJ, Myers RM. Candidate-gene approaches for studying complex genetic traits: practical considerations. Nat Rev Genet. 2002;3:391-7.

40. Staser K, Yang FC, Clapp DW. Plexiform neurofibroma genesis: questions of Nf1 gene dose and hyperactive mast cells. Curr Opin Hematol 2010;17:287-93.

41. Serra E, Rosenbaum T, Nadal M, Winner U, Ars E, Estivill X, Lázaro C. Mitotic recombination effects homozygosity for NF1 germline mutations in neurofibromas. Nat Genet 2001;28:294-6.

42. Wang 0, Montmain G, Ruano E, Upadhyaya M, Dudley S, Liskay RM, Thibodeau SN, Puisieux A. Neurofibromatosis type 1 gene as a mutational target in a mismatch repair-deficient cell type. Hum Genet 2003;112:117-23.

43. Wiest V, Eisenbarth I, Schmegner C, Krone W, Assum G. Somatic NF1 mutation spectra in a family with neurofibromatosis type 1: toward a theory of genetic modifiers. Hum Mutat 2003;22:423-7.

44. Alotaibi H, Ricciardone MD, Ozturk M. Homozygosity at variant MLH1 can lead to secondary mutation in NF1, neurofibromatosis type I and early onset leukemia. Mutat Res 2008;637:209-14

45. Titze S, Peters H, WÃ€hrisch S, Harder T, Guse K, Buske A, Tinschert S, Harder A. Differential MSH2 promoter methylation in blood cells of Neurofibromatosis type 1 (NF1) patients. Eur J Hum Genet 2010;18:81-7.

46. Le L0, Shipman T, Burns DK, Parada LF. Cell of origin and microenvironment contribution for NF1-associated dermal neurofibromas. Cell Stem Cell 2009;4:453-63.

47. Ferner RE. Neurofibromatosis 1. Eur J Hum Genet 2007:15:131-8.

48. Roth TM, Ramamurthy P, Muir D, Wallace MR, Zhu Y, Chang L, Barald KF. Influence of hormones and hormone metabolites on the growth of Schwann cells derived from embryonic stem cells and on tumor cell lines expressing variable levels of neurofibromin. Dev Dyn 2008;237:513-24.

49. McLaughlin ME, Jacks T. Progesterone receptor expression in neurofibromas. Cancer Res 2003;63:752-5.

50. Fishbein L, Zhang X, Fisher LB, Li H, Campbell-Thompson M, Yachnis A, Rubenstein A, Muir D, Wallace MR. In vitro studies of steroid hormones in neurofibromatosis 1 tumors and Schwann cells. Mol Carcinog 2007:46:512-23.

51. Posma E, Aalbers R, Kurniawan YS, van Essen AJ, Peeters PM, van Loon AJ Neurofibromatosis type I and pregnancy: a fatal attraction? Development of malignant schwannoma during pregnancy in a patient with neurofibromatosis type I. BJOG 2003:110:530-2.

52. Byer SJ, Eckert JM, Brossier NM, Clodfelder-Miller BJ, Turk AN, Carroll AJ, Kappes JC, Zinn KR, Prasain JK, Carroll SL. Tamoxifen inhibits malignant peripheral nerve sheath tumor growth in an estrogen receptor-independent manner. Neuro Oncol 2011;13:28-41.

53. Tong JJ, Schriner SE, McCleary D, Day BJ, Wallace DC. Life extension through neurofibromin mitochondrial regulation and antioxidant therapy for neurofibromatosis-1 in Drosophila melanogaster. Nat Genet 2007:39:476-85.

54. Lu J, Sharma LK, Bai Y. Implications of mitochondrial DNA mutations and mitochondrial dysfunction in tumorigenesis. Cell Res 2009:19:802-15.

55. Kurtz A, Lueth M, Kluwe L, Zhang T, Foster R, Mautner VF, Hartmann M, Tan DJ, Martuza RL, Friedrich RE, Driever PH, Wong LJ. Somatic mitochondrial DNA mutations in neurofibromatosis type 1-associated tumors. Mol Cancer Res 2004:2:433-41.

56. Yu M. Generation, function and diagnostic value of mitochondrial DNA copy number alterations in human cancers. Life Sci 2011;89:65-71.

57. Detjen AK, Tinschert S, Kaufmann D, Algermissen B, Nürnberg P, Schuelke M. Analysis of mitochondrial DNA in discordant monozygotic twins with neurofibromatosis type 1. Twin Res Hum Genet 2007;10:486-95.

58. Pasmant E, Sabbagh A, Masliah-Planchon J, Ortonne N, Laurendeau I, Melin L, Ferkal S, Hernandez L, Leroy K, Valeyrie-Allanore L, Parfait B, Vidaud D, Bièche I, Lantieri L, Wolkenstein P, Vidaud M, the members of the NF France Network. Role of Noncoding RNA ANRIL in Genesis of Plexiform Neurofibromas in Neurofibromatosis Type 1. J Natl Cancer Inst 2011;103:1713-22.

59. Beert E, Brems H, Daniëls B, De Wever I, Van Calenbergh F, Schoenaers J, Debiec-Rychter M, Gevaert 0, De Raedt T, Van Den Bruel A, de Ravel T, Cichowski K, Kluwe L, Mautner V, Sciot R, Legius E . Atypical neurofibromas in neurofibromatosis type 1 are premalignant tumors. Genes Chromosomes Cancer 2011;50:1021-32.

60. Ott J, Kamatani Y, Lathrop M. Family-based designs for genome-wide association studies. Nat Rev Genet 2011;12:465-74. 
61. Hindorff LA, Sethupathy P, Junkins HA, Ramos EM, Mehta JP, Collins FS, Manolio TA, et al. Potential etiologic and functional implications of genome-wide association loci for human diseases and traits. Proc Natl Acad Sci USA 2009;106:9362-7.

62. Manolio TA. Genomewide association studies and assessment of the risk of disease. N Engl J Med 2010;363:166-76.

63. Altshuler D, Daly MJ, Lander ES. Genetic mapping in human disease. Science 2008; $322: 881-8$
64. $\mathbf{1 0 0 0}$ Genomes Project Consortium. A map of human genome variation from population-scale sequencing. Nature 2010;467:1061-73.

65. Lander ES. Initial impact of the sequencing of the human genome. Nature 2011;470:187-97.

66. Riccardi VM. Neurofibromatosis type 1 is a disorder of dysplasia: the importance of distinguishing features, consequences, and complications. Birth Defects Res A Clin Mol Teratol 2010;88:9-14

67. Nadeau JH. Modifier genes in mice and humans. Nat Rev Genet 2001;2:165-74. 